\title{
Bcl-2 down-regulation causes autophagy in a caspase-independent manner in human leukemic HL60 cells
}

\author{
K Saeki ${ }^{1}$, A Yuo*,1, E Okuma ${ }^{1}$, Y Yazaki ${ }^{1}$, SA Susin ${ }^{2}$, \\ G Kroemer ${ }^{2}$ and F Takaku ${ }^{1}$ \\ ${ }^{1}$ Department of Hematology, Research Institute, International Medical Center of \\ Japan, 1-21-1 Toyama, Shinjuku-ku, Tokyo 162-8655, Japan \\ 2 Centre National de la Recherche Scientifique-UMR 1599. Institut Gustave \\ Roussy. Pavillon de Recherche I. 39, rue Camille-Desmoulins. 94805 Villejuif, \\ France \\ * Corresponding author: A Yuo, Department of Hematology, Research Institute, \\ International Medical Center of Japan, 1-21-1 Toyama, Shinjuku-ku, Tokyo \\ 162-8655, Japan, Tel: 81-3-3202-7181 ext. 2807; Fax: 81-3-3207-1038; \\ E-mail: yuoakira@ri.imcj.go.jp
}

Received 11.4.00; revised 20.6.00; accepted 7.8.00

Edited by $L$ Fesus

\begin{abstract}
To understand the roles of bcl-2 for the survival of leukemic cells, we constructed human leukemic HL60 transformant lines in which full length bcl-2 antisense message was conditionally expressed by a tetracycline-regulatable expression system. Cell growth was completely inhibited after antisense message induction and massive cell death was induced. Electron microscopic examinations show that cells died by autophagy, but not by apoptosis. The morphology and the function of mitochondria remained intact: neither the reduction in mitochondrial membrane potential nor the nuclear translocation of AIF, a mitochondrial protein that translocates to nuclei in cases of apoptosis, was observed. Caspase inhibitors did not rescue bcl-2-antisense-mediated autophagy. Thus, bcl-2 is essential for leukemic cell survival and its down-regulation results in autophagy. Cell Death and Differentiation (2000) 7, 1263-1269.
\end{abstract}

Keywords: autophagy; bcl-2; antisense; tet-ON; HL60

Abbreviations: AIF, apoptosis-inducing factor; IMDM, Iscove's Modified Dulbecco's Medium; IL-3, interleukin-3; SCF, stem cell factor; PBS, phosphate-buffered saline; WST, 2-(2-methoxy-4nitrophenyl)-3-(4-nitrophenyl)-5-(2,4-disulfophenyl)-2H-tetrazolium

\section{Introduction}

Apoptosis and autophagy, the two central mechanisms for programmed cell death, ${ }^{1-4}$ play important roles for the elimination of malignant cells. Mitochondria ${ }^{5}$ and lysosomes $^{1-4}$ are the key organelles in the execution of apoptosis and autophagy, respectively.
The molecular mechanism of apoptosis has been well studied. In the regulation of apoptosis, bcl-2 family proteins play important roles. An oncogene bcl-2 inhibits apoptosis against various toxic stresses through stabilization of mitochondrial membrane potential $(\Delta \Psi \mathrm{m}) .^{6}$ Expressed on the outer mitochondrial membranes, it blocks the release of apoptosis inducer proteins such as cytochrome $\mathrm{C}^{7,8} \mathrm{AIF}^{9}{ }^{9}$ caspase -9 and caspase- $-2^{10}$ from mitochondria to cytoplasm and thus inhibits the subsequent apoptosis-executing signaling events. It is believed that bcl-2 contributes to tumorigenesis by interfering an appropriate execution of apoptosis against death stimuli. Bcl-2 protein is, however, expressed on other membranous compartments of cells ${ }^{11,12}$ and the roles of bcl-2 outside mitochondria and its effects on autophagy remain unknown.

The physiological roles of bcl-2 family proteins have been studied by gene targeting experiments. In contrast to bcl- $x_{\mathrm{L}}$ knockout mice which are embyonic lethal with massive hemorrhage, ${ }^{13}$ bcl-2 knockout mice are viable with almost intact bone marrow functions. ${ }^{14}$ Thus, bcl-2 does not seem to be required for normal hematopoiesis. The expression of bcl-2 is, however, often enhanced in leukemic cells especially in malignant cases, ${ }^{15}$ suggesting the possible roles of bcl-2 in leukemic cell survival. To address this point and to clarify the roles of bcl-2 in leukemogenesis, we took advantage of a tetracyclineregulatable gene expression system to knockdown $\mathrm{Bcl}-2$ protein in human leukemic HL60 cells.

In this paper we describe the novel extra-mitochondrial role of $\mathrm{Bcl}-2$, showing that down-regulation of $\mathrm{Bcl}-2$ induces an autophagy in leukemic cells. The molecular mechanism of autophagy and possible applications for leukemia therapy will be discussed.

\section{Results}

\section{Bcl-2 down-regulation induces a massive cell death in leukemic HL60 cells}

To study the roles of bcl-2 for the survival of leukemic cells, we took advantage of a tetracycline-regulatable gene expression system. Two transformant lines of human leukemic HL60 cells were prepared, in which the full-length bcl-2 antisense message was inducibly expressed by doxycycline treatment (HL60/tet-antibcl-2). As shown in Figure 1a, Bcl-2 protein expression was apparently reduced after the antisense message induction. On the other hand, no significant changes in $\mathrm{Bcl}-2$ expression were observed in the parental HL60/tet. Two lines of bcl-2-sense-message-expressing transformants were also prepared (HL60/tet-bcl-2), in which $\mathrm{Bcl}-2$ protein expression was up-regulated after doxycycline 
$\mathbf{a}$
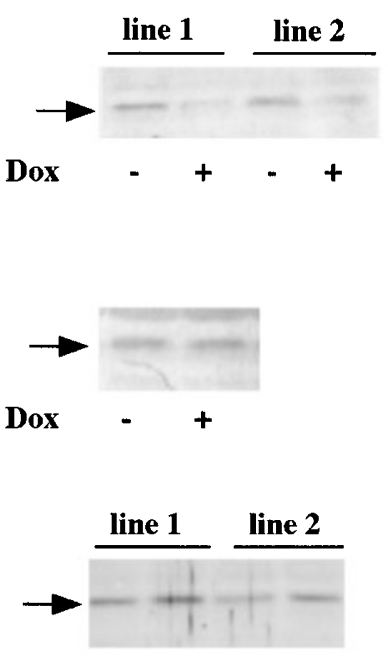

Dox - $+\quad+$ b

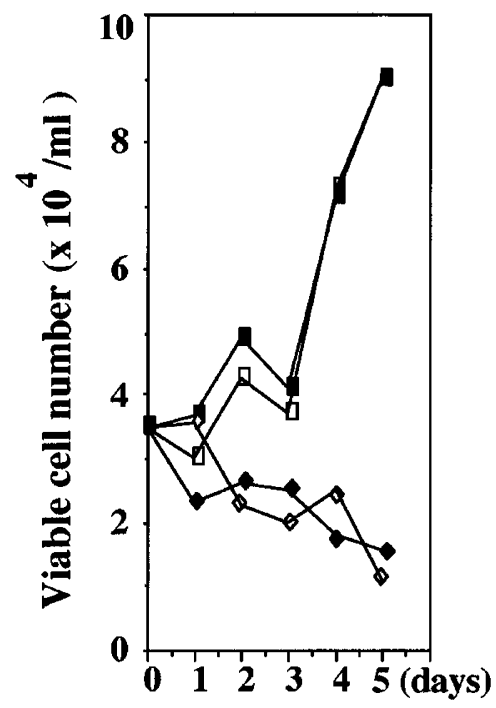

c

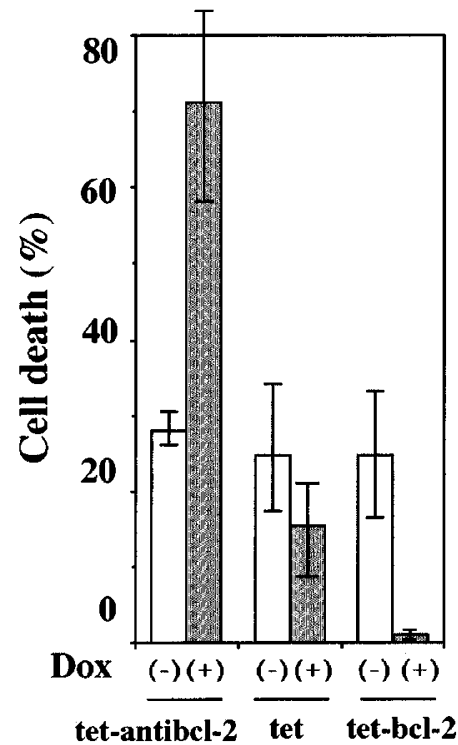

Figure $1 \mathrm{Bcl}-2$ knockdown by its full-length antisense message induction. (a) The two bcl-2-antisense-message-inducible lines of HL60/tet-antibcl-2 (upper), the parental HL60/tet (middle) and the two bcl-2-sense-message-inducible sublines of HL60/tet-bcl-2 (bottom) were cultured with or without $2 \mu \mathrm{g} / \mathrm{ml}$ doxycycline as indicated. After 5 days, cell lysate was prepared from the equivalent number of viable cells and Western blotting was performed. (b) The growth curve of the two lines of HL60/tet-antibcl-2 after doxycycline treatment. (closed square: line-1 doxycycline (-), closed diamond: line-1 doxycycline (+), open square: line-2 doxycycline (-), open diamond: line-2 doxycycline (+)). (c) The percentages of dead cell numbers in HL60/tet-antibcl-2 line 1, HL60/tet and HL60/tet-bcl-2 line 1 at day 5 were shown. Similar results were obtained from line 2 (data not shown). Results from the three independent experiments were shown

$\mathbf{a}$
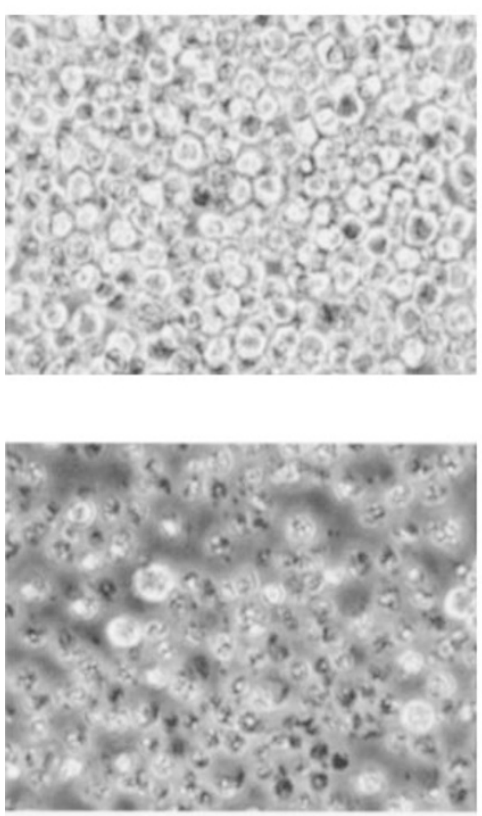

Direct b
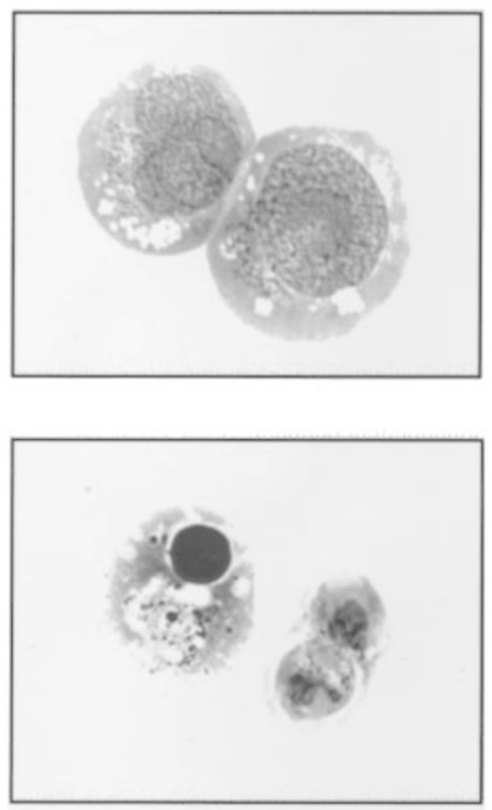

Wright -Giemsa c
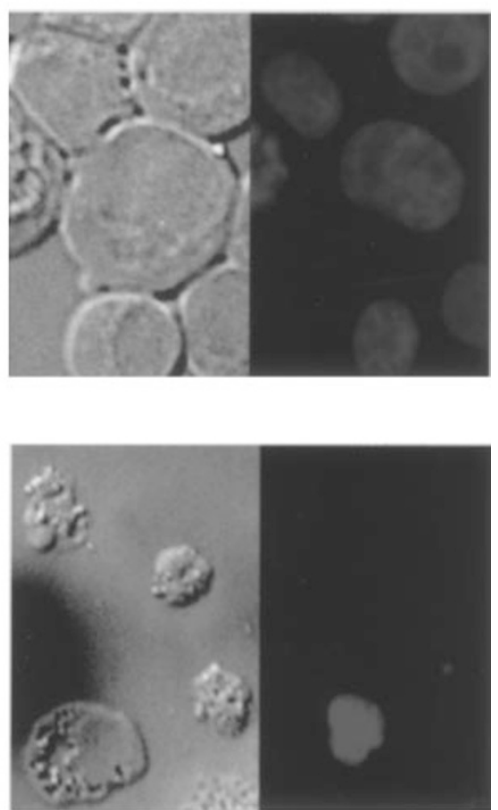

DIC

$\mathbf{H 3 3 3 4 2}$

Figure 2 Light microscopic observations of bcl-2-down-regulated cells. HL60/tet-antibcl-2 cells were cultured for 5 days in the absence (upper) or presence (lower) of doxycycline. (a) The direct microscopic observation (magnitude $\times 100$ ). (b) The Wright-Giemsa staining of the fixed cells (magnitude $\times 1000)$. (c) The photographs by Normarsky differentiated interference contrast (DIC) (left) and by Hoechst 33342 staining (right) (magnitude $\times 400$ ) 
treatment (Figure 1a, bottom). Using these lines we examined the effect of bcl-2 on the survival of leukemic cells. In HL60/ tet-antibcl-2, cell growth was completely inhibited after doxycycline treatment (Figure 1b) and a massive cell death was observed at day 5 (Figures 1c and 2a). In contrast, doxycycline treatment did not affect the growth rate of the parental HL60/tet cells nor HL60/tet-bcl-2 (the percentages of cell number of doxycycline-treated samples against untreated ones at day 5 were $91.7 \pm 7.64 \%$ and $121.0 \pm 10.6 \%$, respectively). Moreover, no significant changes in dead cell numbers were observed in HL60/tet after doxycycline treatment (Figure 1c). Interestingly, cell death was remarkably suppressed in doxycycline-treated HL60/tet-bcl-2 although basal cell death rates without doxycycline did not significantly differ among HL60/tet-antibcl-2, HL60/tet and HL60/tet-bcl-2 cells (Figure 1c). This finding indicates that the up-regulated expression of Bcl-2 effectively inhibits the death which inevitably occurs during the course of in vitro growth as we previously documented as 'the cell-density-dependent apoptosis'. ${ }^{16}$ It also supports that doxycycline treatment per se may not be toxic or advantageous for HL60 survival, but rather, it only functions in the expressional regulation of the genes of interest in our system.

Thus, bcl-2 plays important roles in the control of leukemic cell survival: its down-regulation induces massive cell death and its up-regulation blocks the induction of an unavoidable cell death observed in vitro culture.

\section{Autophagy, but not apoptosis, is induced by bcl-2 down-regulation}

To characterize the cell death induced by bcl-2 downregulation, morphological examinations were performed. Although the direct observation of cultured cells by inverted microscope showed the shrunk features of bcl-2-downregulated cells as in a case of apoptosis (Figure 2a), the light microscopic observation after fixation and staining of cells demonstrated the vacuolous changes of cytoplasm with or without chromatin condensation (Figure $2 b$ ), suggesting that other types of cell death than apoptosis was executed in these cells. Cells were poorly stained with Hoechst fluorochrome (Figure 2c), which was uncommon to apoptosis. An apoptosis-related intra-nucleosomal DNA breakdown was not detected in $2 \%$ agarose electrophoresis (Figure $3 a$ ).
Moreover, we could find only a smear-formed chromosomal DNA breakdown, but not the apoptosis-related $50 \mathrm{kbp}$ DNA cleavage, in $0.3 \%$ agarose electrophoresis (Figure $3 \mathrm{~b}$ ). These findings strongly suggest that certain mechanisms other than apoptosis were carried out in bcl-2-down-regulated cells.

The concept of cell death can be divided into three categories: the classical caspase-dependent apoptosis, the necrosis with edematous or lytic changes of organelles and the autophagy with multiple autophagic vacuole formation in cytoplasm. ${ }^{1-4}$ To understand the cell death mechanism, which had been taken place in bcl-2-down-regulated cells, the electron microscopic examinations were carried out. As shown in Figure 4b, bcl-2-down-regulated cells contained multiple cytoplasmic autophagic vacuoles with intact nuclei. The mitochondria also remained intact with clear crista structure (arrows in Figure 4c). All these findings are compatible to autophagy.

We next examined the mitochondrial function by assessing its membranous potential $(\Delta \Psi \mathrm{m})$. We found no significant changes in the distribution pattern of fluorescence intensity in cells stained by $\Delta \Psi \mathrm{m}$-sensitive dye (Figure 5 ), indicating that the mitochondrial function is well preserved in bcl-2-down-regulated cells. For further confirmation, intracellular localization of AIF, a mitochondrial apoptosis-inducing $\mathbf{a}$

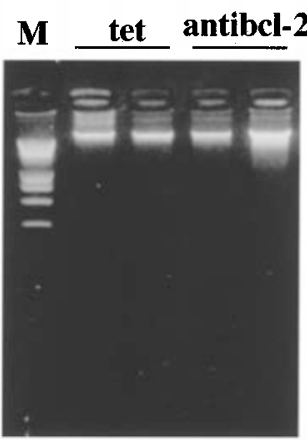

Dox b

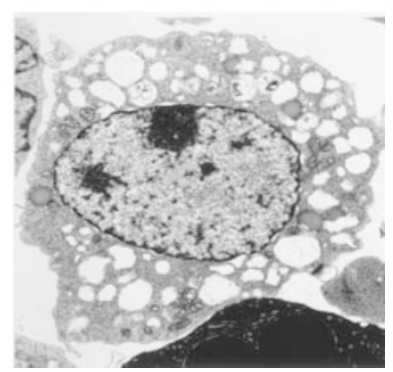

b

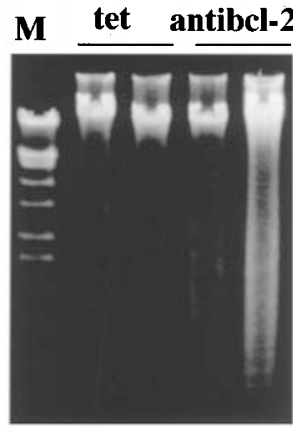

Dox
Figure 3 DNA fragmentation assay. Parental HL60/tet or HL60/tet-antibcl-2 cells were cultured in the absence or presence of doxycycline for 5 days as indicated. The low molecular weight chromosomal DNA was extracted and applied on $2 \%$ agarose $(\mathbf{a})$ or $0.3 \%$ agarose $(\mathbf{b})$ c

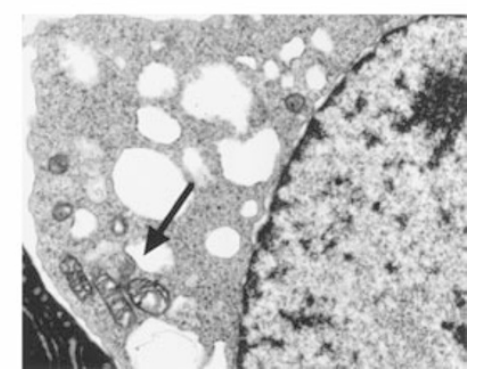

$\mathbf{a}$

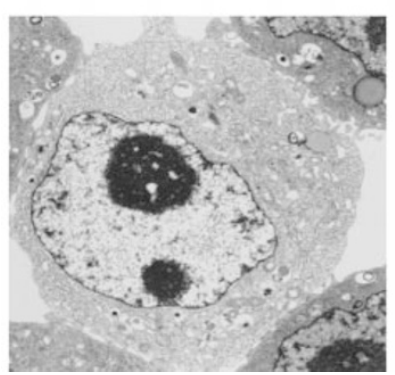

Figure 4 Electron microscopic observations of bcl-2-down-regulated cells. HL60/tet-antibcl-2 cells were cultured for 5 days with or without doxycycline and the electron microscopic observation was performed. Doxycycline-untreated (a) and -treated cells (b, c) (magnitude $\times 1800(\mathbf{a}, \mathbf{b})$ and $\times 3600$ (c)). (An arrow in c indicates the intact mitochondrial crista structure) 
protein that translocates to nuclei following the $\Delta \Psi \mathrm{m}$ reduction in cases of apoptosis, ${ }^{9}$ was examined. Actinomycin D treatment induces apoptosis of HL60 cells ${ }^{17}$ and a greater number of the cells showed nuclear translocation of AIF (Figure 6a). In contrast, the immunostaining pattern of AIF in doxycycline-treated dead HL60/antibcl-2 cells was completely distinct from that of the nuclei (Figure 6b). This finding indicates that AIF did not translocated to nuclei as in cases of apoptosis, but rather, it remained within mitochondria throughout the course of autophagy.

Thus, bcl-2-down-regulation causes autophagy without the impairment of mitochondrial functions.

\section{Caspases are not involved in bcl-2-knockdown- mediated autophagy}

Because bcl-2 is a well-known anti-apoptosis gene, we investigated the possible involvement of apoptosis-related intracellular signaling events in bcl-2-knockdown-mediated autophagy. First we examined the involvement of caspases, the central actors in apoptosis execution. A broad caspase inhibitor, z-VAD-fmk, was added prior to the bcl-2 antisense
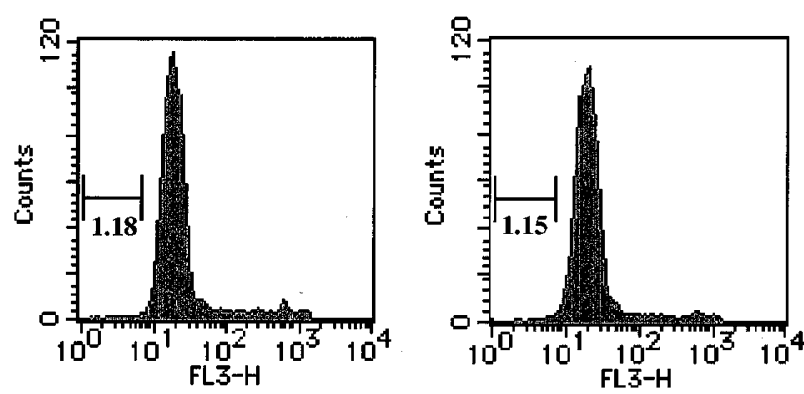

Figure 5 Mitochondrial membrane potential $(\Delta \Psi \mathrm{m})$ assessment. HL60-tetantibcl-2 cells were cultured in the absence (left) or presence (right) of doxycycline for 4 days and mitochondrial membrane potential was examined as described in 'Materials and Methods'. Value in each figure indicates the percentage of the cells with reduced $\Delta \Psi \mathrm{m}$ induction. We found, however, no rescue in the cell viability at day 4 (Figure 7) and day 5 (data not shown), indicating that the bcl-2-down-regulation-induced autophagy was executed in a caspase-independent manner. We next examined the mitochondrial clustering, one of the early events during apoptosis execution, ${ }^{18}$ by staining the cells with anti-AIF antibody for the detection of mitochondria. Interestingly, apparent mitochondrial clustering was observed at day 4 before cell death became evident (Figure 8). Thus, bcl-2 down-regulation induces autophagy by a distinct mechanism from caspase activation although certain signaling events common to apoptosis might be involved.

\section{$\mathrm{Bcl}-2$ protein expression in normal bone marrow CD34 ${ }^{+}$cells}

It is of importance to know the expression level of Bcl-2 protein in normal hematopoietic progenitor cells when bcl-2 knockdown systems are taken into an account for clinical purposes. Western blotting was performed using the lysate of normal human bone marrow $\mathrm{CD} 34^{+}$cells. As shown in Figure 9, we could detect no expression of $\mathrm{Bcl}-2$ protein in freshly isolated CD $34^{+}$cells. When cells were cultured with IL-3 and SCF, a weak expression of Bcl-2 protein was detected but in a lesser amount than in the knockdown HL60 cells. Thus, Bcl-2 protein knockdown to the level of normal $\mathrm{CD}_{3} 4^{+}$cells sufficiently induces autophagy in leukemic cells.

\section{Discussion}

We demonstrated that bcl-2 down-regulation results in an induction of autophagy in human leukemic cells without impairing the mitochondrial functions. Our findings not only determine essential roles of bcl-2 in leukemic cells but also confirm the extra-mitochondrial roles of bcl-2. The involvement of bcl-2 in the regulation of autophagy was suggested by a report, which showed the strong enrichment of $\mathrm{Bcl}-2$ protein on the autophagic vacuoles in aged and neurodegenerativediseased brains. ${ }^{12}$ Our results directly proved that bcl-2 functions in the control of autophagy. $\mathbf{a}$

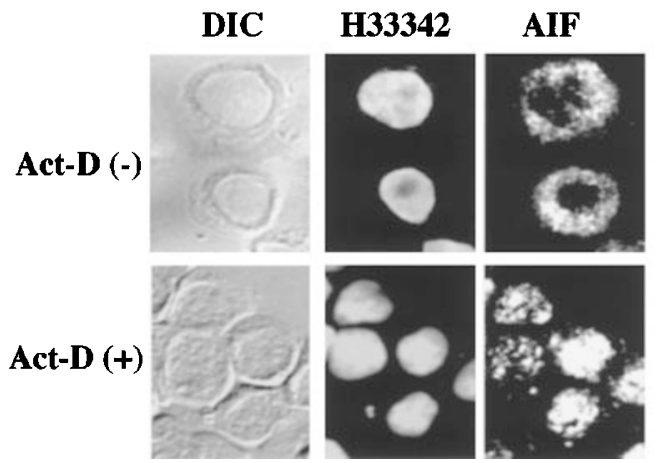

b

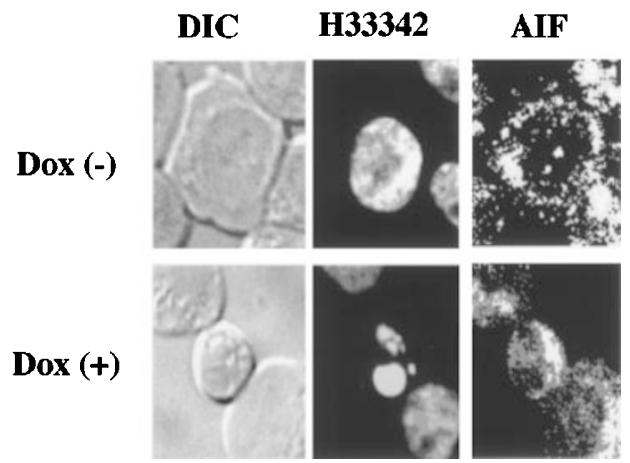

Figure 6 Subcellular localization of mitochondrial AIF protein. (a) HL60 cells were cultured in the absence (upper) or presence (lower) of $1 \mu \mathrm{g} / \mathrm{ml}$ of actinomycin D for $5 \mathrm{~h}$. Examination by Normarsky differentiated interference contrast observation, Hoechst 33342 staining and anti-AIF immunostaining was performed as indicated. (b) HL60/tet-antibcl-2 cells were cultured in the absence (upper) or presence (lower) of doxycycline for 5 days and the examination was performed as in a 
Although the process of autophagy in mammalian cells is not sufficiently understood, recent studies are now unveiling its molecular mechanism. Two genes, beclin- $1^{19}$ and oncogenic ras, ${ }^{20}$ have been identified to be responsible for autophagy. Because oncogenic Rasmediated autophagy could not be blocked by an overexpression of bcl-2, ${ }^{20} \mathrm{bcl}-2$ knock down-mediated autophagy may be executed by other mechanisms. It is of note that Beclin-1 is a Bcl-2-interacting protein. It is suggested

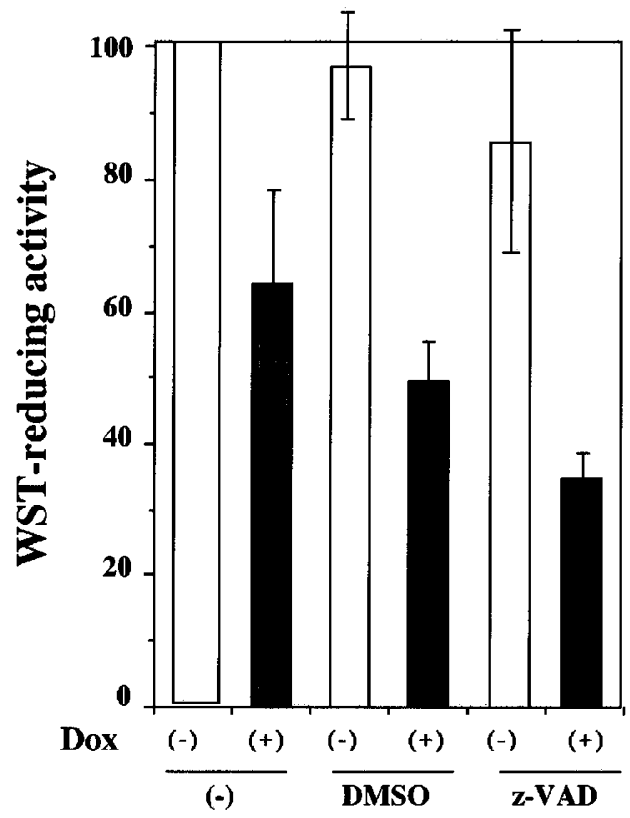

Figure 7 Involvement of caspase activation in bcl-2-down-regulationmediated cell death. HL60/tet-antibcl-2 cells were cultured with or without doxycycline for 4 days in the presence of DMSO or $50 \mu \mathrm{M} z-V A D-f m k$. WSTreducing activity was shown by the percentage to the doxycycline-untreated control (results from three independent experiments were shown) that decreased expression of Beclin-1 contributes to the development of human tumors. ${ }^{19}$ It may be possible that $\mathrm{Bcl}-2$ interferes with the functions of Beclin-1 during the execution of autophagy in malignant cells and thus contributes to tumorigenesis. In this context, an effective knockdown of $\mathrm{Bcl}-2$ protein expression might be a good therapeutic tool for malignant diseases including leukemia. Whether bcl-2 down-regulation has certain toxic effects on normal hematopoietic stem cells is a matter of importance. The absence of hematopoietic disorder in bcl-2 knockout mice suggests that bcl-2 knockdown is not toxic to hematopoietic stem cells. Although bcl-2 antisense oligonucleotides reportedly inhibit $\mathrm{CD} 4^{+}$cell surivival, ${ }^{21}$ this experiment was performed under serum-free conditions. So the in vivo effects of bcl-2 knockdown on the survival of hematopoietic stem cells await further investigations. Anyway, the quiescent hematopoietic stem cells are far more resistant to gene transfer than the proliferating leukemia cells. An effective introduction of fulllength bcl-2 antisense message by certain vectors may be a benefit for leukemia therapy.

\section{Materials and Methods}

\section{Plasmids, cells and reagents}

bcl-2 cDNA was from Professor Tsujimoto (Osaka University Medical School Japan). Its coding region was inserted into the $\mathrm{BamHI}$ site in tetracycline-responsive-element-containing vector of pTRE2 (Clonetech Lab Inc, Palo Alto, CA, USA) either in antisense (pTRE-antibcl-2) or sense (pTRE-bcl-2) direction. Tetracyclinecontroled transactivating factor (rTA)-expression vector of pTet-On (Clonetech) was transfected into HL60 cells by Gene Pulser II electroporation apparatus (Bio-Rad Lab. Alfred Nobel Drive Hercules, CA, USA) and transformants were selected by $800 \mu \mathrm{g} /$ $\mathrm{ml}$ of G418 (WAKO Pure Chemicals Co., Ltd, Osaka, Japan). One

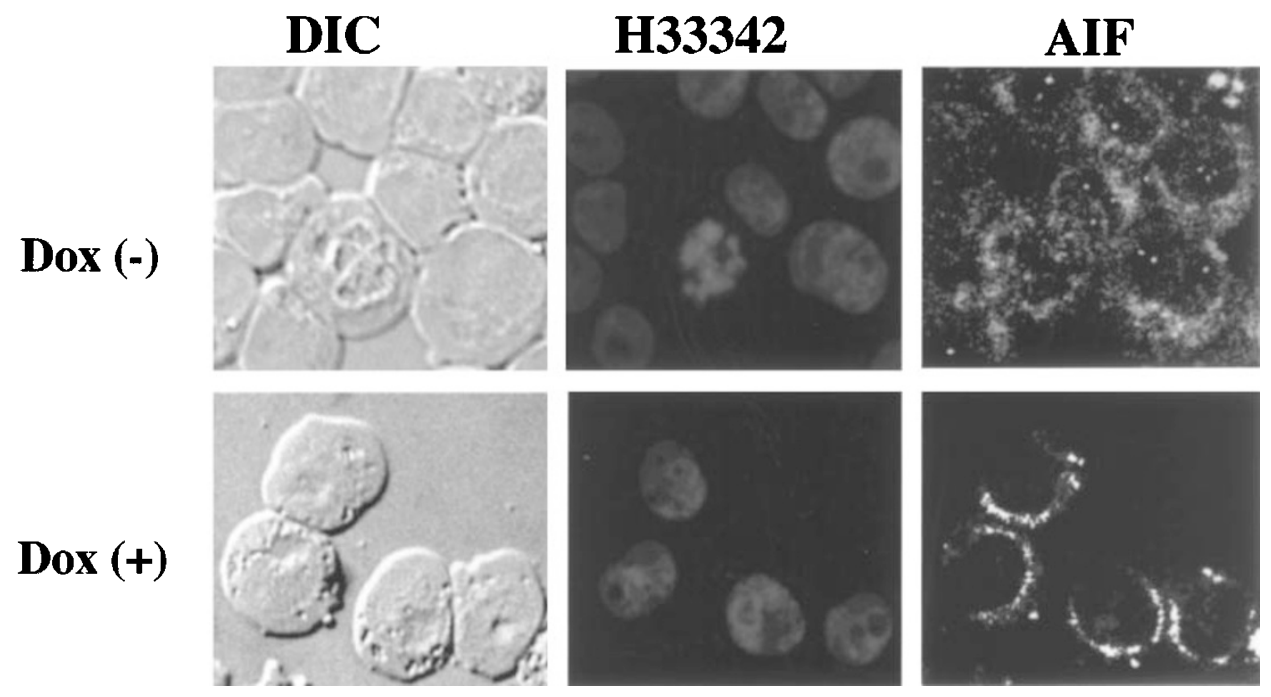

Figure 8 Occurrence of mitochondrial clustering in bcl-2-down-regulated cells. HL60/tet-antibcl-2 cells were cultured in the absence (upper) or presence (lower) of doxycycline for 4 days and subcellular localization of AIF was examined as in Figure 6 


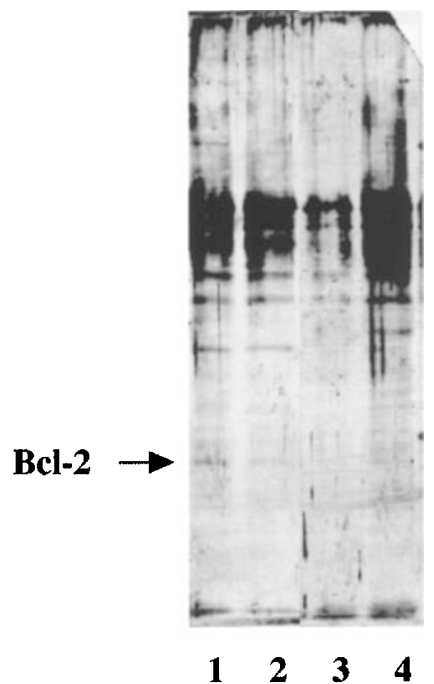

Figure $9 \mathrm{Bcl}-2$ protein expression in normal bone marrow $\mathrm{CD} 34^{+}$cells. Lysates of freshly isolated bone marrow $\mathrm{CD}_{3} 4^{+}$cells (lane 3 ) and cultured $\mathrm{CD} 34^{+}$cells in the presence of IL-3 and SCF for 4 days (lane 4) were applied on polyacrylamide gel, and Western blotting was performed using anti-bcl-2 antibody. In lane 1 and lane 2, lysates of HL60/tet-antibcl-2 cells cultured in the absence and presence of doxycycline for 5 days were applied, respectively. The lysate of an equivalent cell number was applied to each lane $\left(5 \times 10^{4}\right.$ cells/ lane $)$

clone showing about twofold increase in tetracycline-responsiveelement-containing-luciferase reporter activity after 2 days from the addition of $2 \mu \mathrm{g} / \mathrm{ml}$ of doxycycline (Sigma Chemical Co., St. Louis, MO, USA) was selected as HL60/tet. The pTRE-antibcl-2 or pTREbcl-2 was transfected into HL60/tet together with hygromysinresistant-gene-expression-vector of pTK-Hyg (Clonetech) and the transformants were selected by $100 \mu \mathrm{g} / \mathrm{ml}$ of hygromysin. The clones were further selected by checking the decrement or increment of $\mathrm{Bcl}-2$ protein expression after addition of $2 \mu \mathrm{g} / \mathrm{ml}$ of doxycycline. HL60/tet cells were maintained in RPMI1640 (Life Technologies, Inc., Grand Island, NY, USA) supplemented with $10 \%$ heat inactivated fetal calf serum and $800 \mu \mathrm{g} / \mathrm{ml}$ of G418. HL60/tetantibcl-2 and HL60/tet-bcl-2 cells were maintained with further addition of $100 \mu \mathrm{g} / \mathrm{ml}$ of hygromysin. $\mathrm{HL60} /$ tet cells were maintained without hygromysin. Normal $\mathrm{CD} 4^{+}$cells were purchased from Biowittaker Acambrex Co. (Gaithersburg, MD, USA) and cultured with IMDM (Life Technologies) supplemented with $20 \%$ fetal calf serum and $100 \mathrm{ng}$ of IL-3 (Pepro Tech, Inc., Rocky Hill, NJ, USA) and SCF (Pepro Tech) at the cell density of $3 \times 10^{4} / \mathrm{ml}$ in 24 multiwell dish.

\section{Western blotting and immunostaining}

The $5 \times 10^{5}$ cells were lysed by $100 \mu$ of $1 \times$ Laemuli's sample buffer and boiled. The $10 \mu$ lof this lysate was applied to SDS-PAGE using $12.5 \%\left(5 \times 10^{4}\right.$ cells/lane $)$ and transferred to nitrocellulose membrane. Western blotting of Bcl-2 was performed using anti-bcl-2 monoclonal antibody (Pharmingen, San Diego, CA, USA) as the first antibody, and the second antibody reaction and the final detection procedure were performed as previously described. ${ }^{22}$ Immunostaining of AIF was performed as described elsewhere ${ }^{9}$ using cells fixed on slide glasses by cytospin apparatus (Cytospin2, Shandon, Pittsburgh, PA, USA) with further fixation with acetone/methanol solution $(1: 3)$.

\section{Evaluation of cell death by DNA fragmentation, DNA content analysis and morphological examinations}

DNA fragmentation assay was performed by extracting the low molecular weight DNA as previously described. ${ }^{22}$ As DNA molecular marker, marker 4 or marker 7 (Wako Pure Chemicals) was used. Morphological study was performed either by culture microscopy (Olympus Optical Co. Ltd, Tokyo, Japan), by light microscopy for cells stained with Wright and Giemsa solution (Muto Pure Chemical Co., Ltd, Tokyo, Japan), by fluorescent microscopy (Olympus) for immunocytochemically-stained cells or by light microscopy with Normarsky differentiated interference contrast (Olympus). For electronmicroscopic study, cells were directly fixed with $1 \%$ glutaraldehyde and post-fixed with $2 \%$ osmium tetroxide. The cell pellets were embedded in epon resin and cut with an ultramicrotome by $70 \mathrm{~nm}$ thick. The sections were stained with uranyl acetate and lead citrate and photographed by Bio Medical Laboratories Co. Ltd (Tokyo, Japan). ${ }^{16}$

\section{Assessment of mitochondrial membrane potential}

The $5 \times 10^{5}$ cells were collected after 4 days from the induction, washed and resuspended in $500 \mu \mathrm{l}$ of PBS containing $5 \mu \mathrm{g} / \mathrm{ml}$ of Rhodamin 123 (Molecular Probes, Inc. Eugene, OR, USA). Cells were incubated at $37^{\circ} \mathrm{C}$ for $30 \mathrm{~min}$, washed and resuspended in PBS containing $2 \mu \mathrm{g} / \mathrm{ml}$ of propidium iodide (Sigma). Mitochondrial membrane potential was detected by flow-cytometric analysis of Rhodamin 123 accumulation by FACScalibur (Beckton Dickinson, Mountain View, CA, USA). Rhodamin 123 was excited with a $488 \mathrm{~nm}$ argon ion laser; fluorescence emission was measured at $530 \mathrm{~nm}$.

\section{Cell viability assay}

Cell viability was measured by WST-reducing activity using Cell Counting Kit-8 (Wako). The cells were incubated for $2 \mathrm{~h}$ with WST-8 solution, and then the absorbance at $490 \mathrm{~nm}$ (A490) and $595 \mathrm{~nm}$ (A595) was determined.

\section{Acknowledgments}

The authors would like to thank Mrs. Satoko Kida Kitaoka for exellent technical assistance. This work was partially supported by a Grant-in-Aid for the Second Term Comprehensive 10-year Strategy for Cancer Control from the Ministry of Health and Welfare, Japan.

\section{References}

1. Schweichel JU and Merker HJ (1973) The morphology of various types of cell death in prenatal tissues. Teratology 7: 253-266

2. Clarke PG (1990) Developmental cell death: morphological diversity and multiple mechanisms. Anat. Embryol. (Berl) 181: 195-213

3. Zakeri Z, Bursch W, Tenniswood M and Lockshin RA (1995) Cell death: programmed, apoptosis, necrosis or other? Cell Death Differ. 2: 87-96

4. Kitanaka $C$ and Kuchino Y (1999) Caspase-independent programmed cell death with necrotic morphology. Cell Death Differ. 6: 508-515

5. Susin SA, Zamzami N and Kroemer G (1998) Mitochondria as regulators of apoptosis: doubt no more. Biochim. Biophys. Acta. 1366: 151-165

6. Shimizu S, Eguchi Y, Kamiike W, Waguri S, Uchiyama Y, Matsuda H and Tsujimoto $Y$ (1996) Bcl-2 blocks loss of mitochondrial membrane potential while ICE inhibitors act at a different step during inhibition of death induced by respiratory chain inhibitors. Oncogene 13: 21-29 
7. Yang J, LiuX, Bhalla K, Kim CN, Ibrado AM, Cai J, Peng TI, Jones DP and Wang X (1997) Prevention of apoptosis by Bcl-2: release of cytochrome c from mitochondria blocked. Science 275: 1129-1132

8. Kluck RM, Bossy-Wetzel E, Green DR and Newmeyer DD (1997) The release of cytochrome c from mitochondria: a primary site for $\mathrm{Bcl}-2$ regulation of apoptosis. Science 275: 1132-1136

9. Susin SA, Lorenzo HK, Zamzami N, Marzo I, Snow BE, Brothers GM, Mangion J, Jacotot E, Costantini P, Loeffler M, Larochette N, Goodlett DR, Aebersold R, Siderovski DP, Penninger JM and Kroemer G (1999) Molecular characterization of mitochondrial apoptosis-inducing factor. Nature 397: 441-446

10. Susin SA, Lorenzo HK, Zamzami N, Marzo I, Brenner C, Larochette N, Prevost MC, Alzari PM and Kroemer G (1999) Mitochondrial release of caspase-2 and -9 during the apoptotic process. J. Exp. Med. 189: 381-394

11. Krajewski S, Tanaka S, Takayama S, Schibler MJ, Fenton W and ReedJC (1993) Investigation of the subcellular distribution of the bcl-2 oncoprotein: residence in the nuclear envelope, endoplasmic reticulum, and outer mitochondrial membranes. Cancer Res. 53: 4701-4714

12. Migheli A, Cavalla P, Piva R, Giordana MT and Schiffer D (1994) Bcl-2 protein expression in aged brain and neurodegenerative diseases. Neuroreport 5: 1906-1908

13. Motoyama N, Wang F, Roth KA, Sawa H, Nakayama K, Nakayama K, Negishi I, Senju S, Zhang Q and Fujii $S$ (1995) Massive cell death of immature hematopoietic cells and neurons in Bcl-x-deficient mice. Science 267: $1506-$ 1510

14. Nakayama K, Nakayama K, Negishi I, Kuida K, Sawa H and Loh DY (1994) Targeted disruption of Bcl-2 alpha beta in mice: occurrence of gray hair, polycystic kidney disease, and lymphocytopenia. Proc. Natl. Acad. Sci. USA 91: 3700-3704
15. Campos L, Rouault JP, Sabido O, Oriol P, Roubi N, Vasselon C, Archimbaud E, Magaud JP and Guyotat D (1993) High expression of bcl-2 protein in acute myeloid leukemia cells is associated with poor response to chemotherapy. Blood 81: $3091-3096$

16. SaekiK, Yuo A, Kato M, Miyazono K, Yazaki Y and Takaku F (1997) Cell densitydependent apoptosis in $\mathrm{HL}-60$ cells, which is mediated by an unknown soluble factor, is inhibited by transforming growth factor $\beta 1$ and overexpression of $\mathrm{Bcl}-2$. J. Biol. Chem. 272: 20003-20010

17. Martin SJ, Lennon SV, Bonham AM and Cotter TG (1990) Induction of apoptosis (programmed cell death) in human leukemic $\mathrm{HL}-60$ cells by inhibition of RNA or protein synthesis. J. Immunol. 145: 1859-1867

18. LiH, Zhu H, Xu CJ and Yuan J (1998) Cleavage of BID by caspase 8 mediates the mitochondrial damage in the Fas pathway of apoptosis. Cell 94: 491-501

19. Liang XH, Jackson S, Seaman M, Brown K, Kempkes B, Hibshoosh H and Levine B (1999) Induction of autophagy and inhibition of tumorgenesis by beclin 1 . Nature 402: 672-676

20. Chi S, Kitanaka C, Noguchi K, Mochizuki T, Nagashima Y, Shirouzu M, Fujita H, Yoshida M, Chen W, Asai A, Himeno M, Yokoyama S and Kuchino Y (1999) Oncogenic Ras triggers cell suicide through the activation of a caspaseindependent cell death program in human cancer cells. Oncogene 18: 2281 2290

21. Delia D, Aiello A, Soligo D, Fontanella E, Melani C, Pezzella F, Pierotti MA and Della Porta G (1992) bcl-2 proto-oncogene expression in normal and neoplastic human myeloid cells. Blood 79: 1291-1298

22. Saeki K, Yuo A, Suzuki E, Yazaki Y and Takaku F (1999) Aberrant expression of cAMP-response-element-binding protein ('CREB') induces apoptosis. Biochem. J. 343: 249-255 